\begin{tabular}{|c|c|c|}
\hline & $\begin{array}{c}\text { European Association for the } \\
\text { Development of Renewable Energies, Environment } \\
\text { and Power Quality (EA4EPQ) }\end{array}$ & $\begin{array}{l}\text { International Conference on Renewable Energies and Power Quality } \\
\text { (ICREPQ'12) } \\
\text { Santiago de Compostela (Spain), 28th to 30th March, } 2012\end{array}$ \\
\hline
\end{tabular}

\title{
Autonomous MOBILE ROBOT WITH HYBRID PEM FUEL-CELL AND ULTRACAPACITORS ENERGY SYSTEM. DEDALO 2.0
}

\author{
Artal J.S., Dominguez J.A. and Caraballo J. \\ Department of Electrical Engineering. Escuela de Ingeniería y Arquitectura, EINA. \\ University of Zaragoza, Campus Río Ebro. María de Luna $n^{\circ} 3$. \\ Edificio Torres Quevedo, 50018. Zaragoza, Spain. \\ E-mail: jsartal@unizar.es.Phone: 976 762823.Fax 976762226.
}

\begin{abstract}
This paper presents a hybrid configuration combining a hydrogen fuel cell and ultracapacitors to create an energy storage system. Hybrid topology is constructed using a SEPIC converter, which connects the fuel cell with the DC bus whereas a bidirectional Buck-Boost converter links the ultracapacitors group with the DC bus. The main aim is to increase the efficiency of the hybrid power system applied about an autonomous mobile robot. An active Fuel Cell voltage control strategy is presented to manage the power flows. In addition, the overall efficiency of the proposed hybrid power system at overload operation is higher than the conventional one. In this paper, an autonomous mobile robot was converted from a conventional lead-acid or lithium-ion battery to a hybrid PEM Fuel-Cell and ultracapacitors as the power source. The integration of UCaps as element of energy storage on the robot was studied with the aim to improve the energetic solution.
\end{abstract}

\section{Keywords.}

PEM Micro-Fuel Cells, Ultracapacitor, Mobile Robots, Hybrid Power System, Energy/Power Density, Hydrogen, Bidirectional Converter, Capacitive Energy-Storage.

\section{Introduction.}

A fuel cell (FC) is a renewable electrochemical device that directly combines fuel (hydrogen) and oxidant (air) as a means to supply pure energy. They operate with high power density and low temperatures and provide fast startup [1]. However, the fuel-cell varies its voltage in function on the load applied. For instance, the voltage reaches the maximum when no load is applied, whereas it drops as the load currents increases. In order to solve these problems, many papers [2,3] have introduced the combining of fuel cell hybrid power system with a high energy density device (battery or ultracapacitor) to provide transient power. A hybrid power system source can have many favourable characteristics for energy conversion: high efficiency and performance, high power density, faster transient response and reduced fuel cell system volume. Therefore this system can be used in applications, such as in portable electronic devices in which the power demand is variable. A mutual DC bus which parallels different energy sources through a bidirectional dc-dc converter to control the power flows is the most typical configuration, see figure 1, [4] and offers many advantages as more flexibility for applications and excellent behaviour.

Energy management of active hybrid source has already been studied recently, for example by Khaligh et al. [5] who studied the control and regulation of some hybrid system; Gao et al. [6] evaluated the characteristics of a conventional buck-boost hybrid power system; Dixon et al [7] who worked on a hybrid system (ultracapacitors + batteries) for powered vehicles; or by Burke et al [8] who propose different topologies applied in electric, hybrid and fuel cell vehicles, among other authors. Figure 1 show the hybrid system approached as energy source in autonomous mobile robot.

The diagram represents an active hybrid system, where the power distribution between the PEM cell fuel stack and ultracapacitors can be actively controlled by the different dc-dc converters. In this configuration the ultracapacitors substitute the battery system and they are link to DC bus by means of a bidirectional converter, which is parallel to the fuel cell terminals to provide the mobile robot. A regulation strategy for active control is presented to manage the proposed hybrid system, which senses the voltages and current in PEM Fuel Cell and ultracapacitors to estimate the power flows.

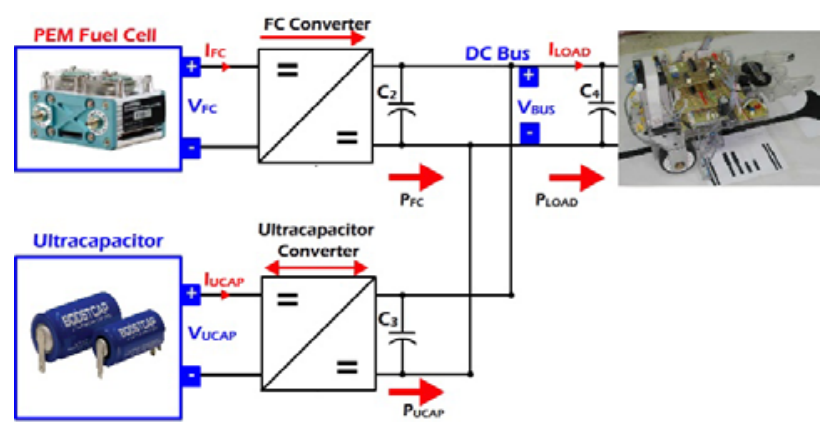

Figure 1. Diagram of the hybrid system consist of PEM fuel cell + ultracapacitor. 


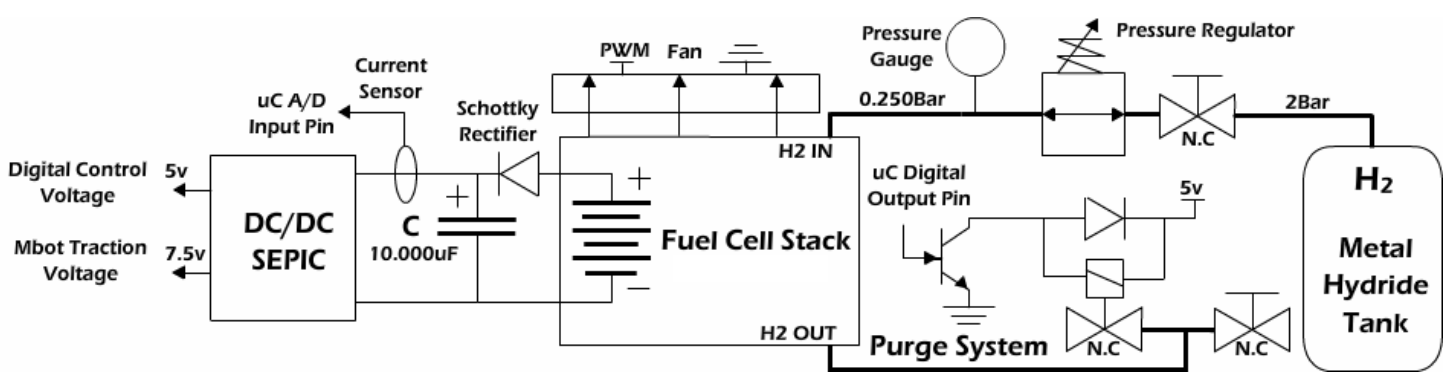

Figure 2. System schematic with the main component in the PEM micro fuel cells.

\section{Micro-Fuel Cell Power-Supply Design.}

The reason why micro-fuel cells were able to raise considerable attention is due to its viability, simplicity and quick start-up. At the core of a PEM micro-fuel cell is a membrane that has some unique property; it is impermeable to gases but can transmit protons. This membrane acts as the electrolyte; it is located between the porous conductive electrodes. Hydrogen ions move across the membrane and the electrons released by the hydrogen thus can be used to form a current through a load. Most options promising fuel cell technologies are the Proton Exchange Membrane PEM which uses a platinum catalyst on the anode and polymer membrane in the electrolyte. There is a wide range of PEM sizes available commercially, due to its ability to use ambient air and be self-humidified from water that it generates. Moreover, this particular PEM micro-fuel cell can be operated with periodically purge, which is necessary to remove excess water that is accumulated from the anode (hydrogen) side. Although the need to purge can be reduced through the temperature, fuel and air flow control. Consequently, an automatic purge algorithm that controlled the voltage and current in the stack terminals has been implemented on the robot microcontroller.

Due to the dimensions of the robot and its small size, a metal hydride storage tank with a capacity of 30 litres (it's based on the intermetallic compound LaNi5), it was redesigned with object of accomplishment to prototype. This one was made in Bulgaria by the company LabTech Ltd. A pressure regulator developed for metal hydrides was used to control the hydrogen flow from the tank to the stack. In this way, the supply pressure to the stack was fitted to 3psi (250mbars), approximately. A manual valve allows the opening or closing of the hydrogen tank. Unlike the lead acid battery, which would normally require 8 hours recharge after being fully depleted, a hydrogen tank or a 10 minutes refill has been enough to get the robot going again. A direct comparison of material energy densities used in fuel cells and batteries ignores the contributions to weight and voltage that their support system need. This cause is especially important in mobile or portable applications where the weight and volume of the peripheral equipment must be included.

High purity hydrogen (99,997\%) and air -oxygen- were utilized as anode and cathode supply, respectively. In this application the micro-fuel cell is composed of 14 cells connected in series (fuel-cell H30, manufacturer Horizon
Company). Thereby his maximum power is 30 watts, while that the open circuit voltage $(\mathrm{OCV})$ is $+12,8 \mathrm{~V}$ that is an average voltage of $+0,92 \mathrm{~V} /$ cell. Micro-fuel cell selected has total dimensions of $80 \times 47 \times 75 \mathrm{~mm}$ approximately. The hydrogen is provided by a metalhydride container. This indicates that the stability and reliability of the present fuel cell stack are, to certain extent, satisfactory. PEM fuel cell will generate heat during his operation while the metal hydride will absorb heat when the system is working, the more serious part is that the fuel-cell stack will be shut down if the temperature is over $60^{\circ} \mathrm{C}$, and the metal hydride could not release hydrogen if the temperature is too low.

Two ventilators placed in front of the fuel cell improve the system efficiency, stabilizing in addition the internal temperature. This temperature must be around $30 / 40^{\circ} \mathrm{C}$. Ventilators voltage is controlled by means of a PWM provide by the microcontroller, which allows changing the air flow (and therefore the oxygen) that crosses the stack, depending on diverse parameters as the temperature, humidity and current. At PEM's, the water production on the air side (cathode) and the need to keep the membrane moisturized produces an excess of water which is accumulated on the anode (hydrogen) side. This event provides a loss of efficiency in the fuel cell, diminishing the voltage of their membranes. For this reason, a purge automatic system has been designed to keep the balance between the moisture and the fuel cell performance. The time between purges and the duration of the same ones form part of the parameters to consider. Figure 2 shows a schematic of the system with the following components: storage metal-hydride tank, PEM micro-fuel cell, SEPIC dc-dc converter, pressure regulator and water purge line.

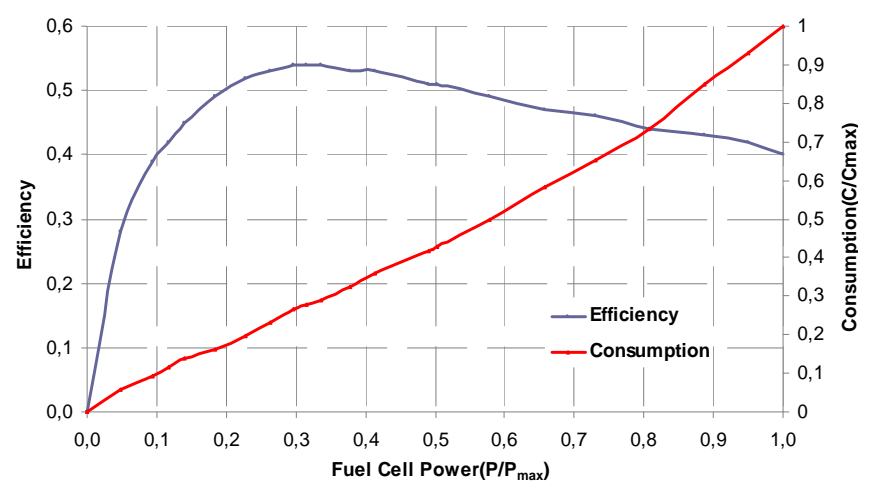

Figure 3. Power converter efficiency and hydrogen consumption coefficient $\left(C / C_{\max }\right)$ as function in the power ratio $\left(P / P_{\max }\right)$ in the PEM fuel-cell. 
In Fuel-Cell the efficiency depends on the output power, ratio $\mathrm{P} / \mathrm{P}_{\max }$. It's assumed that the maximal efficiency ideal is $\eta_{\mathrm{ST}}=0,617$. Efficiency diagram of the fuel cell used in this application is shown in the figure 3. To achieve a good fuel economy, the FCS should be avoided the operation in this poor efficiency region. Hereby, the maximum efficiency of the system is reached for a ratio corresponding to $\mathrm{P} / \mathrm{P}_{\max }=0,3$ approximately; where $\mathrm{P}$ corresponds with power dedicated to the load whereas $\mathrm{P}_{\max }$ is the nominal power in the Fuel-Cell. The implemented algorithm has as aim to operate in the proximities of the ideal point (maximum efficiency) of the system -tracking-. In this point the consumption ratio $\mathrm{C} / \mathrm{C}_{\max }$ of hydrogen in the fuel cell system is equivalent to value $C / C_{\max }=0,26$.

In the dynamic model of fuel cell system [9], the output voltage $\mathrm{v}_{\mathrm{FC}}$ is defined using and empirical relationship as follow (1).

$$
v_{F C}=E_{O C V}-v_{A C T}-v_{O H M}-v_{C O N C}
$$

Here, $\mathrm{E}_{\mathrm{OCV}}$ is the open circuit voltage (internal voltage in fuel cell stack); $\mathrm{v}_{\mathrm{ACT}}, \mathrm{v}_{\mathrm{OHM}}$ and $\mathrm{v}_{\mathrm{CONC}}$ represent activation, ohmic and concentration losses respectively, which are caused by various physical or chemical factors. Therefore, the output voltage of PEMFC is unstable with load current changing. Fig. 4 illustrates the relationship between the parameters current, voltage and power in the fuel cell stack



Figure 4. Experimental curve polarization H-30. Relation between the current, voltage and power in the diagram fuel-cell stack.

The fuel consumption rate $\mathrm{m}_{\mathrm{H} 2}$ is related to the stack current follows [10],

$$
m_{H 2}=\frac{N_{c e l l} \cdot M_{H 2}}{n \cdot F} \lambda \cdot I_{\text {stack }}
$$

In this equation $\mathrm{N}_{\text {cell }}$ represent the cell number $\left(\mathrm{N}_{\text {cell }}=14\right)$, $\mathrm{M}_{\mathrm{H} 2}$ indicate the molar mass of hydrogen $\left(\mathrm{M}_{\mathrm{H} 2}=2 \mathrm{~g} / \mathrm{mol}\right)$, $n$ represent the number of electrons working in the reaction $\left(\mathrm{n}=2 \mathrm{e}^{-}\right), \mathrm{I}_{\text {stack }}$ is the stack current in the FCS, F indicate the Faraday constant $(\mathrm{F}=96,487 \mathrm{C} / \mathrm{mol})$ and $\lambda$ represent the hydrogen excess ratio $(\lambda=1,2)$. The objective of an optimal control is to minimize the total hydrogen consumption.
In order to classify different hybrid systems, the so called hybridization degree (HD) is used. According to Jeong, the level can be calculated as follows [11],

$$
H D=1-\frac{P_{F C_{-} \max }}{P_{\text {System }_{-} \max }} ; 0 \leq H D \leq 1
$$

Where $\mathrm{P}_{\mathrm{FC} \_ \text {max }}$ is the maximum fuel cell power and $\mathrm{P}_{\text {System_max }}$ is the maximum system of power installed. The HD coefficient can adopted values between 0 (pure fuel cell vehicle) and 1 (pure battery).

For the start up of the system, the manual valve of the metal-hydrides must be opened allowing the hydrogen flow towards the stack. In this moment the stack begins to produce energy for the dc-dc converter. A microcontroller PIC $12 \mathrm{~F} 675$ of the manufacturer Microchip, who is fed across a small button battery (its supply does not depend on the condition of the fuel cell) monitors the process of beginning and controlling the procedure of purge. Hereby, when the stack voltage reaches a minimum value, it allows the operation of the fans and initiates the dc-dc converter. A Schottky diode is necessary in the exit terminal of the stack to prevent them from circulating inverse currents.

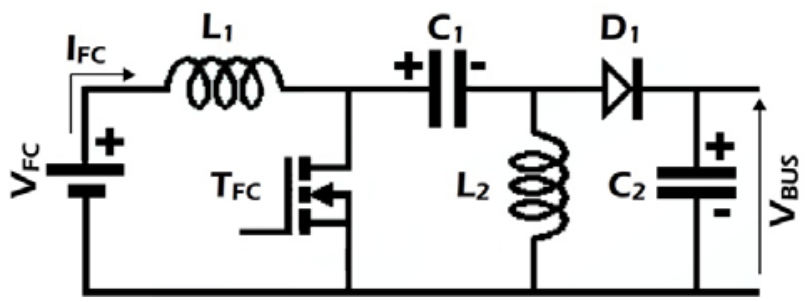

Figure 5. Proposed simple SEPIC circuit. The converter allows the output voltage to be greater than, less than or equal to the input voltage (PEM Fuel Cell) in DC-DC conversion.

Other additional need for a small mobile prototype will be the efficient conversion of power supply to regulate. Converters provide this characteristic using high-speed switching technology to provide suitable voltages at high efficiencies (dc-dc converter have an efficiency around 90\%). SEPIC converter (Single-Ended Primary Inductor Converter), figure 5, can both step up and step down the input voltage, while maintaining the same polarity and the same ground reference for input and output. The input to the converter will be the wide operating voltage range of the PEM Fuel Cell. This allows that the input voltage can vary while providing a relatively constant voltage to the mobile robot. The input current in the converter is continuous and thus it needs smaller volume of input filter. Unfortunately, the SEPIC topology is difficult to understand and requires two inductors, $\mathrm{L}_{1}$ and $\mathrm{L}_{2}$. The two inductors can be wound on the same core since the same voltages are applied to them throughout the switching cycle.

The output voltage of the SEPIC is controlled by the duty cycle "D" of the control transistor (4). Thus independently of the Fuel Cell voltage, the DC bus is kept constant to value $\mathrm{V}_{\mathrm{DC}}=+7,5 \mathrm{~V}$. This converter is 
similar to the buck-boost converter, but has advantages that the isolation between its input and output (provided by a capacitor in series). It has become popular in recent years in battery-powered systems that must step up or down depending upon the charge level of the battery. Equations of the SEPIC converter are:

$$
D=\frac{V_{\text {OUT }}}{V_{\text {OUT }}+V_{I N}} \quad V_{\text {OUT }}=V_{I N} \frac{D}{1-D}
$$

\section{Ultracapacitors Power-Supply Design.}

Ultracapacitors are becoming the component of choice for engineers and designers with applications requiring shortterm or peak (burst) power [4]. They are ideally suited as stand-alone solutions for short-term power requirements ranging from a few seconds to minutes. The charge in these devices is realized in seconds whereas lead-acid batteries often require hours, thus potentially benefiting quick-charge applications. Moving toys, such as miniature racing cars or mobile robots, also benefit from the fastcharge properties of the UCaps which can be charged just before use. Moreover they have a large modularity with respect to voltage and capacitance, ultra-low internal resistance, low self-discharge and can be produced at low cost. All these characteristics have been demonstrated with a minimal degradation.

Ultracapacitor can be discharged or charged faster than batteries -in matter of seconds it can be recharged again for use- and can deliver 10-25 times more power e.g. UCaps typically have a specific power of around $2000 \mathrm{~W} / \mathrm{kg}$ [6], as well as a much lower charge time when compared to lead-acid batteries. Double-Layer Capacitor also offers 10100 times the energy density (Wh/kg) of conventional capacitors. In terms of energy and power density, ultracapacitors can therefore be placed between batteries and conventional capacitors $[6,8,12]$, see figure 6 .

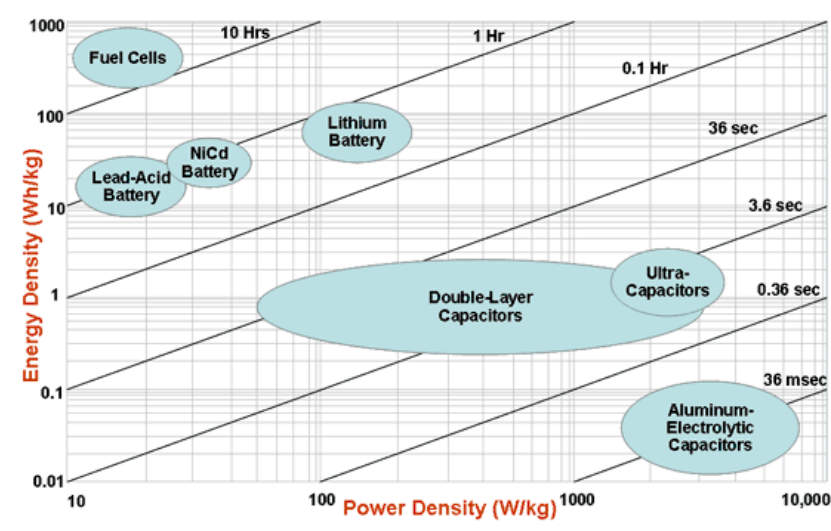

Figure 6. A Ragone chart storage device energy density versus power density on a log-log coordinate system, with discharge times represented as diagonals.

The reason why electrochemical capacitor were able to raise considerable attention are visualized in figure 6 , where typical energy storage and conversion devices are presented in the so called "Ragone diagram" in terms of their specific energy (Wh/kg) and specific power (W/kg).
Due to the micropores in the activated carbon material used in the electrodes, the UCaps has a specific high surface area up to $3000 \mathrm{~m}^{2} / \mathrm{g}$. This property combined with a short distance between the opposite charges (the thickness of the double-layer depends on the concentration of the electrolyte and the size of ions, which is in the order of 5-10 $\AA$ Angstrom for concentrated electrolytes) allows an increase in both parameters: capacitance and energy. As indicated Burke [6], the specific capacitance of activated carbon can vary over a wide range $(100-250 \mathrm{~F} / \mathrm{g})$ depending on as it is processed and the electrolyte used in the cell [13].

Ultracapacitors are power devices with excellent performance over a wide temperature range including both hot and extreme cold conditions. The capacitance of the complete ultracapacitors module is based on the number of individual capacitors cells connected in series or parallel. In this way, if " $n$ " is the cells number in series and " $\mathrm{m}$ " is branches number in parallel, the capacitance of the module can be calculated according (5).

$$
C_{\text {Total }}=C_{\text {Cell }} \frac{m}{n} \quad R_{\text {Total }}=R_{\text {Cell }} \frac{n}{m}
$$

Where, $\mathrm{R}_{\text {Total }}$ represent the total ESR -Equivalent Series Resistance- that it contributes to energy loss during capacitor charging and discharging $\left(\mathrm{I}^{2} \mathrm{R}\right)$ and $\mathrm{C}_{\text {Total }}$ represent the capacitance of the ultracapacitor bank, respectively. Just, $\mathrm{R}_{\text {cell }}$ and $\mathrm{C}_{\text {cell }}$ represent the internal resistance and capacitance of individual ultracapacitor cell $[14,15]$. Note also that RC time constant in ultracapacitors is usually too long $\tau_{\mathrm{C}}=\mathrm{ESR} \times \mathrm{C}$ (capacitors response time seconds; polymer-film, ceramic electrostatic $\cong 10^{-9} \mathrm{~s}$; aluminium electrollytic $\cong 10^{-4} \mathrm{~s}$; electrochemical UCaps $>1$ s).

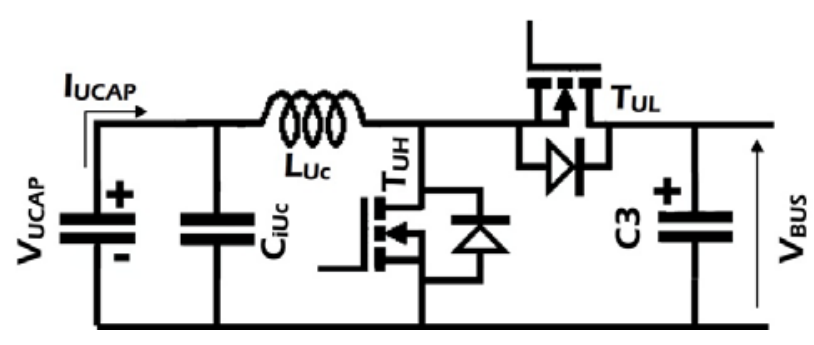

Figure 7. Proposed simple Buck-Boost circuit. The converter bidirectional allows the charge-discharge of the ultracapacitors.

Bidirectional Buck and Boost PWM converter, see figure 7 , is another well know switched-mode converter. It can either increase or decrease the magnitude of the DC voltage. A hysteresis control was select in this case due to its easy implementation. This converter is used to interface an ultracapacitors to the main power bus of a mobile robot. In this circuit, both switches are composed of a transistor together with an antiparallel diode. They can conduct current in both directions, but can support the voltage in only one direction. In other words, the switches are bidirectional for the current and unidirectional for the voltage. These are two-quadrant switches, which permit energy flow in both directions, 
from left to right and vice versa. In discharge mode, the bidirectional buck-boost converter is used to raise the UCaps voltage to the DC voltage bus level. Equations of the UCaps bidirectional Buck-Boost converter are (6):

$$
V_{O_{-} B U C K}=V_{I N} D \quad V_{O_{-} B O O S T}=V_{I N} \frac{1}{1-D}
$$

When the power generated by the PEM fuel cell is more than the power needed for the mobile robot, the UC converter act as a buck converter and charge the ultracapacitor group. In buck operation the power flow goes from DC bus to UCaps. During the transient conditions, the ultracapacitor will supply the robot; in this case the UC converter will act as a boost converter. In boost operation the power flow goes from UCaps to DC bus.

Figure 8 illustrates the simplicity of the design. It shows the MicroBot prototype during an experimental test (charge/discharge cycles). In this particular design, four cells (BCAP0350 Maxwell, 350F/cell) were used in series and/or parallel combination $\mathrm{n}=\mathrm{m}=2\left(\mathrm{C}_{\text {Total }}=350\right.$ Farads, $\mathrm{R}_{\text {Total }}=3,2 \mathrm{~m} \Omega$ ), to obtain a maximum voltage in the UCaps of $+5,4 \mathrm{~V}$ (2,7V/cell). The energy extracted " $\Delta \mathrm{E}_{\mathrm{UCap}}$ " from an ultracapacitors string depends on the voltage variations in the cells, (7).

$$
\Delta E_{\text {UCap }}=\frac{1}{2} C\left(V_{\max }^{2}-V_{\min }^{2}\right)
$$

The minimum voltage value " $\mathrm{V}_{\min }$ " allows estimating the energy extracted of the UCaps during the discharge (7), $\Delta \mathrm{E}_{\mathrm{UCap}}=4928 \mathrm{~J}$ or $\Delta \mathrm{E}_{\mathrm{UCap}}=1,37 \mathrm{Wh}$. The voltage variation " $\Delta \mathrm{V}_{\mathrm{UCaps}}$ ", represents the change during the discharge of the ultracapacitor. This is determined by knowing the maximum voltage $\left(\mathrm{V}_{\max }\right)$ and the minimum allowable voltage $\left(\mathrm{V}_{\min }=+1 \mathrm{~V}\right)$. Often the present minimum voltage specification is limited by a component of the system.



Figure 8. Mobile robot prototype together with the new hybrid supply system formed by ultracapacitors + PEM Fuel Cell.

Power electronics can be used between the PEM Fuel Cell, UCaps and the MBot, keeping a constant voltage value in the robot. It should be noted that the use of a DC/DC converter is optional but it permits to increase the system efficiency (decrease the discharge voltage value in the UCaps without to expose the robot to excessively low voltage). Therefore in some applications, the use of ultracapacitors and micro fuel cells together with a DC/DC converter reduces the number of cells required in the power supply.

The power losses or ultracapacitors heating is proportional to current squared times the duty cycle. Charging UCaps is one of the simple aspects of power management. During a charge process the voltage must be controlled to ensure that it does not exceed the rated voltage of the cells. A constant current charge process is particularly useful to check this parameter. The assumption is that the UCaps will never be charged above the combined maximum voltage rating of all the cells. Having voltages above rating will reduce the life of UCaps cell proportionally to the overvoltage value. If the excess is high enough, cell failure may occur rapidly.

Other main characteristic is the low impedance cell, Equivalent Series Resistance - ESR $=3,2 \mathrm{~m} \Omega$. When an UCap is fully discharged it will appear as a small resistance to many charges and will draw as much of the source current as is available unless limited. Therefore, a constant current or constant power charger will need to be used. When charge time is critical, constant power charging provides the fastest method.

\section{Application Example: Logistic Centre.}

Hybrid PEM Fuel-Cell and ultracapacitor power-supply here described has been implemented in "Dedalo 2.0", a small autonomous mobile robot -colloquially called MicroBot-. This unit forms part of a robot group with a logistics orientated purpose, where each of them has different systems of energy storage (e.g. lead-acid or lithium-ion batteries, ultracapacitors and hydrogen fuelcells). This distinguishing characteristic has allowed us to compare the goodness and deficiencies in the different energy sources applied to low-power robotic devices. As example to comment that "Teseo" (the first MBot constructed, see figure 9) has a lead-acid battery, which introduces a deadweight motivated by the battery size $\left(\right.$ mass $\left._{\mathrm{LA}}=870 \mathrm{~g}\right)$ in relation to the Ucaps used in "Ulises" (mass $_{\mathrm{UC}}=360 \mathrm{~g}$ ) or Lithium-Polymer batteries used in "Hefesto" (mass $\left.{ }_{\mathrm{LP}}=190 \mathrm{~g}\right)$. In the present case, the power supply system of the hybrid mobile robot "Dedalo 2.0" has an approximate weight of mass $_{\mathrm{HY}}=920 \mathrm{~g}$ including the fuel cell, ultracapacitors and metal hydride storage tank $\mathrm{H}_{2}$. This overweight involves an increase in the energetic consumption and a minor efficiency in the vehicles.

Once reached this one, MicroBot will capture the piece and will transport it to the destination or final point. That way the example of logistic application simulates a small automated warehouse or factory, where the robot makes a complete cycle of search and location. At present, the importance that acquires the automatic warehouse management has caused that the industry develops great quantity of commercial devices destined to the traffic of goods in logistic centers. 
Figure 9 shows a small detail of the environment in the logistic plant taken as reference and its structure has a shape of grid. In our case it has been considered a black line on white background as indicator of possible paths along which the different MBots drive. The grid is formed by 16 intersections or crossings, which simulate the different path of a warehouse. Every robot has a set of sensors and actuators that allow its navigation and orientation of an autonomous form. Material delivery place remains pre-established for the PC by means of wireless communication. Navigation system has is able to rectify the way if during the displacement he finds some obstacle in his way. Moreover it can calculate alternative routes (orientation and navigation algorithm) to reach the destination with the load.



Figure 9. Mobile robot "Teseo" moving a small object to the destination station.

\section{Conclusions.}

The paper described some of the most conventional methods to store energy for mobile robot, such as Micro PEM fuel cell systems and ultracapacitors, showing the advantages and disadvantages of each one of them. An autonomous mobile robot has been proposed as an efficient design tool for a system approach. Dedalo 2.0 was converted from a conventional lead-acid battery to a hybrid system based on PEM Fuel Cell and ultracapacitors as the power source. The integration of UCaps as elements of energy storage on the robot was studied with the aim of optimizing the energetic solution.

To study the characteristics of the hybrid PEM fuel cell and ultracapacitors power supply system, a mobile robot is an ideal platform because of its suitable power range, easier implementation and low cost. In particular emphasis is given to the role of low-power electronics as the enable for a correct decoupled power and energy. A reason for considering UCaps for a particular application is their long shelf and cycle life. Higher-voltage ultracapacitors technology arises on the horizon and the implications are enormously far-reaching.

\section{Acknowledgements.}

The authors would like to thank Foundation for Development of the new Hydrogen Technologies in
Aragón together with the University of Zaragoza (Spain) for financially support this research in this project.

\section{References}

[1]. Junbo J., Gucheng W., Youyi W. and Ming H. "Electrical Characteristic Study of a Hybrid PEMFC and Ultracapacitor System” IEEE Transaction on Industrial Electronics. Vol. 57, issue 6, pp 1945 to 1953. June 2010.

[2]. Gao L., Dougal R.A. and Liu S. "Power Enhancement of an Actively Controlled Battery Ultracapacitor Hybrid”. IEEE Transaction on Power Electronics. January 2005, vol. 20, issue 1, pp 236 to 243.

[3]. Gao L., Jiang Z. and Dougal R.A. "Evaluation of active hybrid fuel cell/battery power sources". IEEE Transaction on Aerospace and Electronic Systems. Vol. 41 issue 1, pp 346 to 355. Jan 2005.

[4]. Maher B., Dogterom J. and Fisher T. "Fuel Cells and Ultracapacitors: a Proven Value Proposition versus Incumbent Technologies". 28th Annual International Telecommunications Energy Conference, INTELEC06, pp 1 to 4. September 2006.

[5]. Khaligh A. and Zhihao Li. "Battery, Ultracapacitor, Fuel Cell and Hybrid Energy Storage Systems for Electric, Hybrid Electric, Fuel Cell and Plug-In Hybrid Electric Vehicles: State of the Art". IEEE Transactions on Vehicular Technology. Volume 59, issue $n^{\circ}$ 6. July 2010, pp 2806 to 2814.

[6]. Andrew Burke. "Ultracapacitors: Why, How and Where is the Technology". Elsevier Science. Journal of Power Sources 2000, volume 91, pp 37 to 50.

[7]. Juan Dixon. "Energy Storage for Electric Vehicles". International Conferene on Industrial Technology, ICIT 2010. 14-17 March, pp 20 to 25.

[8]. Burke A.F. "Batteries and Ultracapacitors for electric, hybrid and fuel cell vehicles". Proceedings of the IEEE. April 2007, vol. 95, issue 4, pp 806 to 820.

[9]. C.H. Zheng, C.E. Oh, Y.I. Park and S.W. Cha. "Fuel economy evaluation of fuel cell hybrid vehicles based on equivalent fuel consumption". Elsevier Science Direct. International Journal of Hydrogen Energy, 2011. Vol. 1 issue 7. [10]. Jeong K.S. and Oh B.S. "Fuel economy and life-cycle cost analysis of a fuel cell hybrid vehicle". Elsevier Science Direct. Journal of Power Sources 2002, volume 105, pp 58 to 65.

[11]. Miller J.M., Deshpande U. and Rosu M. "Carbon-Carbon Ultracapacitor Equivalent Circuit Model, Parameter Extraction, and Application". Maxwell Technologies Inc. Ansoft Ansoft First Pass Workshop. Irvine CA. October 2007.

[12]. Bobby Maher. "A Backup Power System Using Ultracapacitors". Power Electronics Technology, September 2004. http://www.powerelectronics.com.

[13]. Burke A., Miller M. and Parker N. "Ultracapacitor Technology: Present and Future Performance and Applications". Proceedings of the Advanced Capacitor World Summit 2003. Washington DC, August 2003.

[14]. Runtz K.J. and Lyster M.D. "Fuel Cell Equivalent Circuit Models for Passive mode Testing and Dynamic mode Design". Canadian Conference on Electrical and Computer Engineering. May 2005 pp 749 to 797.

[15]. Woonki N., Taesik P., Taehyung K. and Sangshin K. "Light Fuel-Cell Hybrid Electric Vehicles Based on Predictive Controllers". IEEE Transactions on Vehicular Technology, vol. 60, no 1 . January 2011, pp 89 to 97. 